\title{
Knowledge, Attitude and Behaviors of Adults About Adulthood Immunization
}

\author{
Erişkinlerin Erişkin Aşıları Hakkındaki Bilgi, Tutum ve Davranışları
}

\author{
Arzu Uzuner ${ }^{l}$, Şule Arabacl ${ }^{1}$, Ata İsmail Yüceel ${ }^{1}$, Ali Cem Kocatürk ${ }^{1}$, Ebru Kaynar ${ }^{1}$, Abdulhakeem Khan ${ }^{1}$
}

\begin{abstract}
Background and Objective: While newborn and childhood vaccination is widely known and utilized worldwide, adult immunization is not applied widely. Therefore, about 30,000 adults die yearly from preventable diseases. The routine vaccination of adults are considered unsatisfactory also in our country. The aim of this research is to evaluate the knowledge, attitude and behaviors of adults about adulthood immunization in Maltepe, Istanbul. Methods: An observational and descriptive study was carried out in Maltepe, Istanbul between March 20th and May 6th, 2016 in a total of 16 family health centers which were randomly selected from each neighbourhood. A questionnaire form inquiring the socio-demographic characteristics, knowledge, attitude and behaviors about adult immunization was applied with face-to-face interviews to participants who were over the age of eighteen. Results: A total of 318 participants were

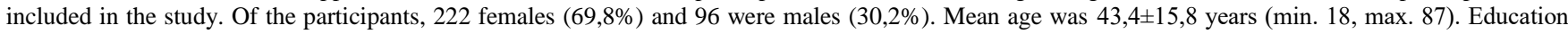
level was high school and above in $55 \%$ of the subjects. The most commonly known vaccine was the influenza vaccine $(89,3 \%)$, the least known vaccine was the shingles vaccine $(32,3 \%)$. While tetanus vaccine was the most commonly used $(42,1 \%)$ followed by, the $23,9 \%$ for influenza $(23,9 \%)$, and hepatitis B $(18,2 \%), 0,3 \%(n=1)$ had been vaccinated for HPV. The confidence for the effectiveness of the vaccines was the highest for hepatitis B $(60,4 \%)$, and the lowest for influenza $(40,9 \%)$ and HPV $(48,1 \%)$. Media was the most commonly used source of knowledge about adult vaccination $(27,7 \%)$. A statistically significant difference was not detected between the patients who had/did not have a chronic disease or the patients who were using medications regularly or not with regard to vaccination against influenza, pneumococcus and tetanus ( $>>0.05)$. The most common reasons for not getting vaccinated were "having insufficient knowledge about the vaccine" $(42,5 \%)$ and "deeming it unnecessary" $(41,2 \%)$. Conclusion: The results of the study have revealed that the participants did not have sufficient knowledge about adult vaccination and vaccination rates were low. So it may be targeted to improve the knowledge level of the community through using media and primary care institutions as effective sources of knowledge.
\end{abstract}

Keywords: Adult vaccines, immunization

\section{ÖZET}

Giriş ve Amaç: Yenidoğan ve çocukluk dönemi aşıları hakkında tüm dünyada farkındalık ve uygulamalar varken, erişkin aşılamaları yaygın uygulama alanına sahip değildir. Bundan dolayı erişkin dönemde aşılla önlenebilen hastalıklardan dolayı ölümler dünya çapında yılda 30.000 kişiyi bulmaktadır. Ülkemizde de erişkinlerin rutin bağışıklaması eksik kabul edilmektedir. Bu araştırmanın amacı Maltepe ilçesindeki erişkinlerin erişkin aşıları hakkındaki bilgi, tutum ve davranışlarını değerlendirmektir. Gereç ve Yöntem: Araştırma İstanbul Maltepe ilçesinde 20.03-06.05.2016 tarihlerinde gözlemsel ve tanımlayıcı olarak gerçekleştirildi. Maltepe ilçesinin 16 mahallesinin her birinden randomizasyonla belirlenen toplam 16 Aile Sağlık Merkezi (ASM)'nde yürütüldü. Sosyodemografik özellikleri ve erişkin aşıları hakkında bilgi, tutum ve davranışları sorgulayan bir anket formu belirlenen tarihler arasında başvuran 18 yaş üzerindeki bireylere yüz yüze görüşme yöntemiyle uygulandı. Bulgular: Araştırmaya toplam 318 kişi dahil edildi. Katılımcıların 222'si (\%69,8) kadın, 96'sı

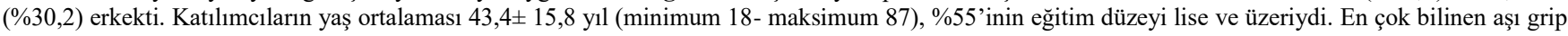
aşısı $(\% 89,3)$, en az bilinen aşı zona aşısıydı $(\% 32,3)$. Erişkin dönemde katılımcıların en çok yaptırdığı aşı tetanoz (\%42,1), grip (\%23,9), Hepatit B $(\% 18,2)$ aşısı iken en az yaptırılan aşıysa HPV $(\% 0,3)$ aşısı olarak saptandı. Aşıların koruyuculuğuna güvenme oranı en yüksek sıklıkta Hepatit B (\%60,4) aşısında, en düşük oranda grip $(\% 40,9)$ aşısı için belirtildi. Erişkin aşıları hakkında en cok bilgi edinilen kaynak medyaydı (\%27,7). Kronik hastalığı olan/olmayan ve düzenli ilaç kullanan ya da kullanmayanlar arasında grip, tetanoz ve pnömokok aşılarını yaptırma açısından anlamlı düzeyde fark saptanmadı $(p>0.05)$. Așıları yaptırmayanların en çok belirttiği gerekçeler așı hakkında bilgilendirilmemiș olma $(\% 42,5)$ ve așıyı kișisel olarak gerekli görmemiș $(\% 41,2)$ olmalarıydı. Sonuçlar: Araştırma, katılımcıların erişkin aşıları hakkında yeterli düzeyde bilgi sahibi olmadıklarını ve aşılanma oranlarının düşük olduğunu ortaya koymuștur. Buna göre halkın erişkin aşıları hakkında bilgi düzeyinin arttırılması hedeflenebilir. Bu amaçla etkili bilgi kaynağı olarak medya ve birinci basamak sağlık kurumları kullanabilir.

Anahtar kelimeler: Erişkin aşıları, bağışıklama

Received / Geliş tarihi: 27.11.2017, Accepted / Kabul tarihi: 02.07.2018

${ }^{1}$ Marmara Üniversitesi Tıp Fakültesi Aile Hekimliği Anabilim Dalı

*Address for Correspondence / Yazışma Adresi: Ata İsmail Yüceel, Marmara Üniversitesi Tıp Fakültesi Aile Hekimliği Anabilim Dalı İstanbulTÜRKIYE, E-mail: atayuceel@hotmail.com

Uzuner A, Arabacı Ş, Yüceel Aİ, Kocatürk AC, Kaynar E, Khan A. Erişkinlerin Erişkin Aşıları Hakkındaki Bilgi, Tutum ve Davranışları. TJFMPC, 2018;12 (3): 215-225. DOI: $10.21763 /$ tjfmpc.452487 


\section{GİRIŞ}

Aşı yoluyla bağışıklık kazanımı enfeksiyonlara bağlı olarak ortaya çıkan sağlık sorunlarını azaltmak ve ortadan kaldırmaya yönelik en etkili ve başarılı halk sağlığı stratejisidir. ${ }^{1}$ Buna bir örnek olarak 1980 yılına gelindiğinde çiçek aşısı sayesinde çiçek hastalığı yeryüzünden tamamen yok edilmiş olması gösterilebilir. Polio aşısı ile dünyadaki polio insidansı \%99 oranında azalmış, milyonlarca çocuğun ölümü aşılar sayesinde önlenmiştir. ${ }^{2}$ Aşı ile bağışıklama yaşam boyu devam eden bir süreçtir. Yenidoğan ve çocukluk dönemi aşıları hakkında tüm dünyada bir farkındalık ve uygulama varken, erişkin dönem aşılamaları her ülkede yaygın ve rutin uygulama alanına sahip değildir. ${ }^{3}$ Erişkin aşılama şemasında 2012 yılında bazı düzenlemeler yapılmıştır. Buna göre 18 yaş ve üzerindeki tüm erişkinlere yılda bir doz influenza; birisi tetanoz, azaltılmış difteri ve azaltılmış boğmaca (Tdap) olmak üzere yaşam boyunca 10 yılda bir doz tetanozdifteri (Td); kadınlarda 12-26, erkeklerde 12-21 yaşları arasında üç doz Human Papilloma Virus (HPV); iki doz varicella, bir veya iki doz kızamıkkızamıkçık-kabakulak (KKK); 60 yaş ve üzeri erişkinlere tek doz herpes zoster ve 65 yaş üstündekilere ise bir doz konjuge ve polisakkarit pnömokok aşılarının uygulanması önerilmektedir. Son yapılan bir araştırmada 12-15 yaş aralığındaki ergenlerde iki doz HPV aşısının yeterli immünite sağlama açısından yeterli olduğu gösterildi. ${ }^{4}$ Ayrıca tıbbi, mesleki, yaşam tarzı gibi diğer endikasyonların varlığında bir veya iki doz pnömokok, iki doz hepatit-A, üç doz hepatit-B, bir veya daha fazla doz meningokok aşısı uygulanması gerekmektedir. ${ }^{5}$ Amerika'da 2025 ila 2030 y1lları arasında sadece 200 çocuğun aşıyla önlenebilen hastalıklar yüzünden ölmesi beklenirken, yetişkinlerdeyse bu rakamın 70.000 civarında olacağı tahmin edilmektedir. ${ }^{5}$ Aynı zamanda erişkin bireylerin aşılamasının gerektiği gibi yapılamaması, kronik hastalığı ve multimorbiditeleri olan bireyleri enfeksiyonlara karşı daha savunmasız hale getirmektedir. Son yüzyılda temiz suya erişimin artması, aşıların bulunması ve diğer birçok faktör sebebiyle popülasyonun yaşam beklentisi logaritmik bir şekilde artmıştır. Bunun sonucunda küresel popülasyon giderek yaşlanmaktadır. Önümüzdeki 50 yılda 80 yaşın üzerindeki insan sayısının günümüzün 3 katına çıkacağı, toplam dünya popülasyonunun \%20'sinin 65 yaş ve üzerindeki bireylerden oluşması beklenmektedir., ${ }^{6,8}$ Yaşam süresinin artmasıyla kişilerin immün sistemleri de zayıflamakta, çocukluk çağında yapılan aşıların etkinliği giderek azalmaktadır. Bu yüzden erişkin aşılaması mortalite ve morbiditenin azaltılması açısından büyük önem taşımaktadır. Havayolu seyahatlerinin yaygınlaşması, birlikte havayoluyla bulaşı gerçekleşen hastalıkların görülmesini oldukça artırmıştır. ${ }^{9}$ Bununla birlikte bir çalışmada aşılanmayan popülasyonu oluşturan bireylerin en yüksek risk grubunda olan bireyler olduğu gözlenmiştir. ${ }^{10}$ İngiltere'de boğmaca daha önceden sadece yenidoğan aşı uygulamasında yer alırken 2008 ila 2012 y1lları arasında boğmacanın insidansı $\% 50$ oranında arttı̆̆ için yetişkin aşıları arasına alınmıştır. ${ }^{11}$ Boğmaca aşısı yeni doğanlarda yeterli immünite sağlayamadığı için ergen ve yetişkinlerle birlikte sağlık çalışanları ve gebelerin aşılanmasına başlayan bazı ülkeler vardır. $\mathrm{Bu}$ aşılama yenidoğanlarda boğmacaya karşı dolaylı bağışıklık sağlar. $\mathrm{Bu}$ "koza stratejisi" olarak adlandırılmaktadır. ${ }^{12}$ Koza stratejisi uygulayan ülkelere Avusturya, Belçika, Yunanistan, Almanya, İtalya, Çek Cumhuriyeti ve Macaristan'1 örnek gösterebiliriz ${ }^{13}$. Dünya genelinde 2011 yılında "Küresel boğmaca girişimi" başlatılmış olup; önce adolesan aşılaması ve ardından erişkin aşılaması yapılması kararı alınmıştır. Ancak ülkemizde "Koza projesi" olarak da anılan bu proje yaygın olarak uygulanamamıştır. ${ }^{14}$ Hepatit A virüsü ise dünya çapında yaygınlık göstermekte ve her yıl 1,4 milyon yeni vaka kayıtlara eklenmektedir. ${ }^{15}$ Ülkemizde birçok insan erişkinlerde aşı ile önlenebilen hastalıklara karşı aşılanmamıştır ve genellikle böyle bir aşılamanın var olduğundan haberdar değillerdir. Ülkemizde 2004 yılında yapılan bir araştırmaya göre, 2004 yılı içerisinde erişkinlerde tetanoz nedeniyle 33 ölüm ve 532 hastaneye yatış öyküsü; influenzaya bağlı 101 ölüm ve 13696 hastaneye yatış öyküsü bulunmaktadır. ${ }^{16} \mathrm{Bu}$ araştırmada amaçlanan erişkinlerin, erişkin dönemde aşılanma hakkındaki bilgi, tutum ve davranışlarının incelenmesidir. Bu sayede erişkinlerin aşılanmasına yönelik çeşitli stratejiler belirlenebilir.

\section{YÖNTEM}

\section{Araştırmanın Tasarımı}

$\mathrm{Bu}$ çalışma, Maltepe ilçesinde 18 yaş ve üzeri bireylerin erişkin aşıları hakkındaki bilgi, tutum ve davranışlarını araştırmak amacıyla gözleme dayalı tanımlayıcı bir araştırma olarak tasarlandı. Araştırmanın etik kurul onayı Kasım 2015'te Marmara Üniversitesi T1p Fakültesi Etik Kurulu'ndan (09.2015.372, 70737436-050;06.04-) ve araştırmanın Aile Sağlığı Merkezlerinde (ASM) gerçekleştirilebilmesi için izin İstanbul İl Halk Sağlığı Müdürlüğü’nden alındı (03.2016).

\section{Örneklem Seçimi}

Araştırmanın örneklemi \%95 güvenilirlik düzeyi, erişkin aşıları hakkında bilgi düzeyi \%71 sıklık öngörüsü ${ }^{20}$ ve 0.05 kabul edilebilir hata oranı ile Maltepe ilçesinin erişkin nüfusu olan 353.000 toplam popülasyonda 317 katılımcıya ulaşılması gerektiği hesaplandı, 318 kişiye ulaşıldı. Maltepe ilçesinde yer alan 18 mahallede hizmet veren toplam 40 ASM içinden 16'sı kura ile belirlendi, iki mahalle 
güvenlik nedeniyle çalışma dışı bırakıldı.

\section{Verilerin Toplanmast}

İzinler alındıktan sonra veri toplanmasına Mart ayında başlandı. Belirlenen Aile Sağlığ 1 Merkezlerinde sorumlu hekimden izin alınarak muayene olmaya gelen erişkinlere araştırma hakkında bilgi verildi, onayı alınan bireyler araştırmaya dahil edildi. Her bir ASM'de görüşülecek kişi sayısı 16 ASM' ye bölünerek belirlendi. On altı soruluk anket sosyodemografik verileri, güncel sağlık durumu hakkında soruları ve erişkin aşıları hakkındaki bilgi, tutum ve davranışları ölçen likert skalalar içermektedir.

\section{Anketin Özellikleri}

Erişkinlerin aşılanma hakkındaki bilgi, tutum ve davranışlarının değerlendirilmesi amaçlanan ankette katılımcılara toplamda 22 soru yöneltildi. İlk 6 soruda katılımcılara aşılar hakkındaki tutumlarının bağlı olduğu değişkenlerin değerlendirilmesi amacıyla demografik özellikleri hakkında (yaş, cinsiyet, medeni durum, sosyal güvence, eğitim durumu ve çalışma durumu) sorular yöneltildi, 7.-11. sorularda katılımcılar kronik hastalıkları, kullandıkları ilaçlar, aşı olmalarına engel durumlar açısından sorgulandı. Daha sonra katılımcıların likert tipteki bir skalada aşıları duyup duymadıkları, yaptırıp yaptırmadıkları ve kendilerini aşının koruduğu hastalık açısından risk altında görüp görmedikleri sorgulandı; yaptırmadıkları aşı varsa neden yaptırmadıkları sorusu da yöneltildi. Burada kişilerin aşılar hakkındaki sergilediği tutum ve bu tutuma sebep olabilecek durumların öğrenilmesi amaçland. Daha sonra gelen 14 . ve 18. sorular arasında da katılımcılara aşılar hakkında bilgi soruları yöneltildi. Katılımcılara aynı zamanda aşılar hakkındaki davranışlarını belirleyecek olan erişkin aşılarının koruyuculukları hakkındaki düşünceleri, sigortanın aşıları karşılayıp karşılamadığı, aşılar hakkında bilgi edinilen kaynaklar konularında da soru yöneltildi. Ankette yer alan tutum ve davranıș sorularında Aşık ve ark. nın ${ }^{17}$ araştırmasındaki sorulardan da yararlanıldı.

\section{İstatistiksel Analiz}

Veriler SPSS 20 programında analiz edildi. Verilerin sıklık ve yüzdelik dağılımları saptandı, bağımlı ve bağımsız değişkenler karşılaştıııldı. Kategorik değişkenlerin karşılaştırmalı analizlerinde ki-kare ve "fisher's exact" testler kullanıldı. Yapılan testlerde anlamlılık değeri $p<0.05$ olarak belirlendi.

\section{BULGULAR}

Kattlımcıların Sosyodemografik ve Tıbbi Özgeçmiş Özellikleri
Katılımcıların yaş ortalamaları $43,4 \pm 15,8$ y1l idi (min. 18, max. 87).

\begin{tabular}{|c|c|c|}
\hline \multicolumn{3}{|c|}{$\begin{array}{l}\text { Tablo 1. Katılımcıların sosyodemografik } \\
\text { tıbbi özgeçmiş özelliklerinin dağılımı }\end{array}$} \\
\hline Özellikler & $\begin{array}{l}\text { Sayı } \\
(\mathbf{s})\end{array}$ & $\begin{array}{l}\text { Yüzde } \\
\%\end{array}$ \\
\hline \multicolumn{3}{|l|}{ Cinsiyet ( $\mathrm{s}=318)$} \\
\hline Kadın & 222 & 69,8 \\
\hline Erkek & 96 & 30,2 \\
\hline \multicolumn{3}{|l|}{ Yaş $(\mathrm{s}=314)$} \\
\hline $18-35$ & 107 & 34,0 \\
\hline $36-64$ & 174 & 55,5 \\
\hline $65+$ & 33 & 10,5 \\
\hline \multicolumn{3}{|l|}{ Medeni durum $(s=317)$} \\
\hline Evli & 239 & 75,4 \\
\hline Bekar & 78 & 24,6 \\
\hline \multicolumn{3}{|l|}{ Eğitim düzeyi (s=318) } \\
\hline Sadece okur-yazar & 10 & 3,1 \\
\hline İlkokul mezunu & 101 & 31,8 \\
\hline Ortaokul mezunu & 32 & 10,1 \\
\hline Lise mezunu & 95 & 29,9 \\
\hline Üniversite mezunu & 90 & 28,3 \\
\hline \multicolumn{3}{|l|}{ Çalışma durumu $(\mathrm{s}=318)$} \\
\hline Çalışıyor & 94 & 29,6 \\
\hline Çalışmiyor & 224 & 70,4 \\
\hline \multicolumn{3}{|l|}{ Sosyal güvence durumu(s=317) } \\
\hline SGK & 276 & 87,1 \\
\hline SGK+Özel kurum & 6 & 1,9 \\
\hline Özel kurum & 10 & 3,2 \\
\hline Yeşil kart & 9 & 2,8 \\
\hline Yok & 16 & 5,0 \\
\hline \multicolumn{3}{|l|}{ Tibbi özgeçmiş özellikleri (s=318) } \\
\hline Kronik hastalık varlığg & 158 & 49,7 \\
\hline Düzenli olarak ilaç kullanımı & 157 & 49,4 \\
\hline $\begin{array}{l}\text { Düzenli olarak doktor kontrolüne } \\
\text { gitme }\end{array}$ & 149 & 46,9 \\
\hline Așı olmaya engel tedavi alma & 33 & 10,4 \\
\hline
\end{tabular}




\section{Katılımcıların Erişkin Aşıları Hakkında Bilgi, Tutum Ve Davranış Durumları}

Katılımcıların 112’si $(\% 35,2)$ erişkinlere aşı uygulandığından haberdar olmadığını belirtti.

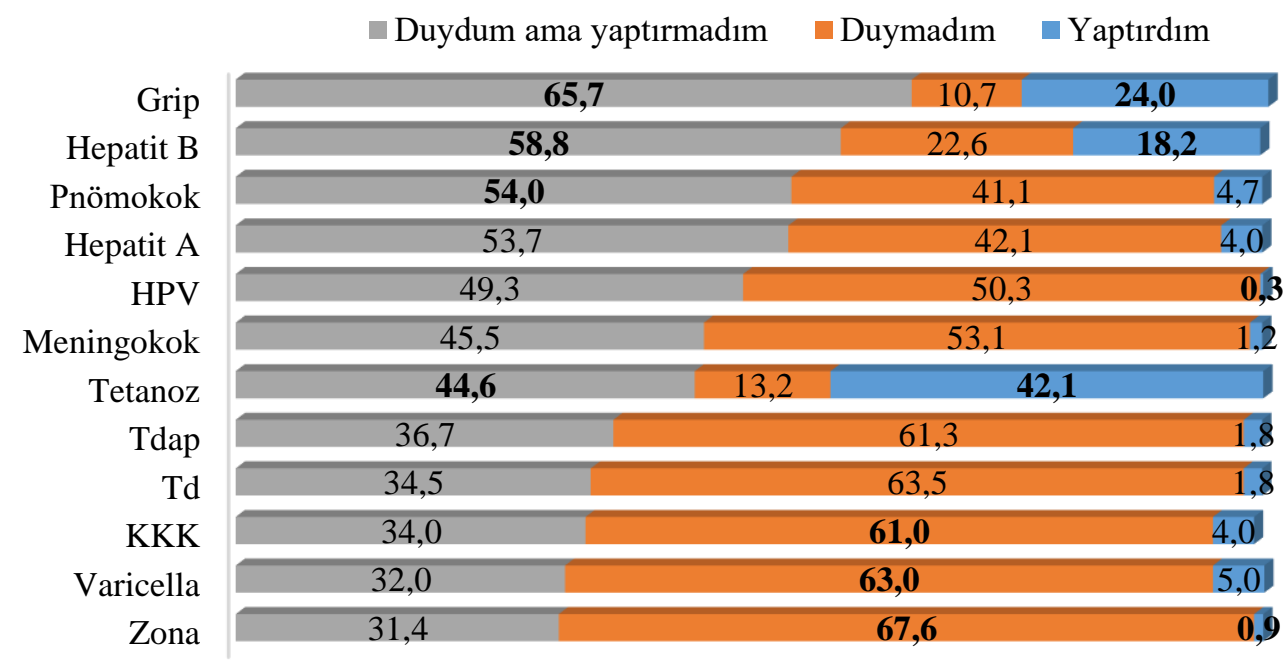

Grafik 1: Katılımcıların erişkin aşılarını duyma ve yaptırma oranları (\%)

Katılımcıların Bireysel Risk Değerlendirmesi ve Aşılara Güvenme Durumları

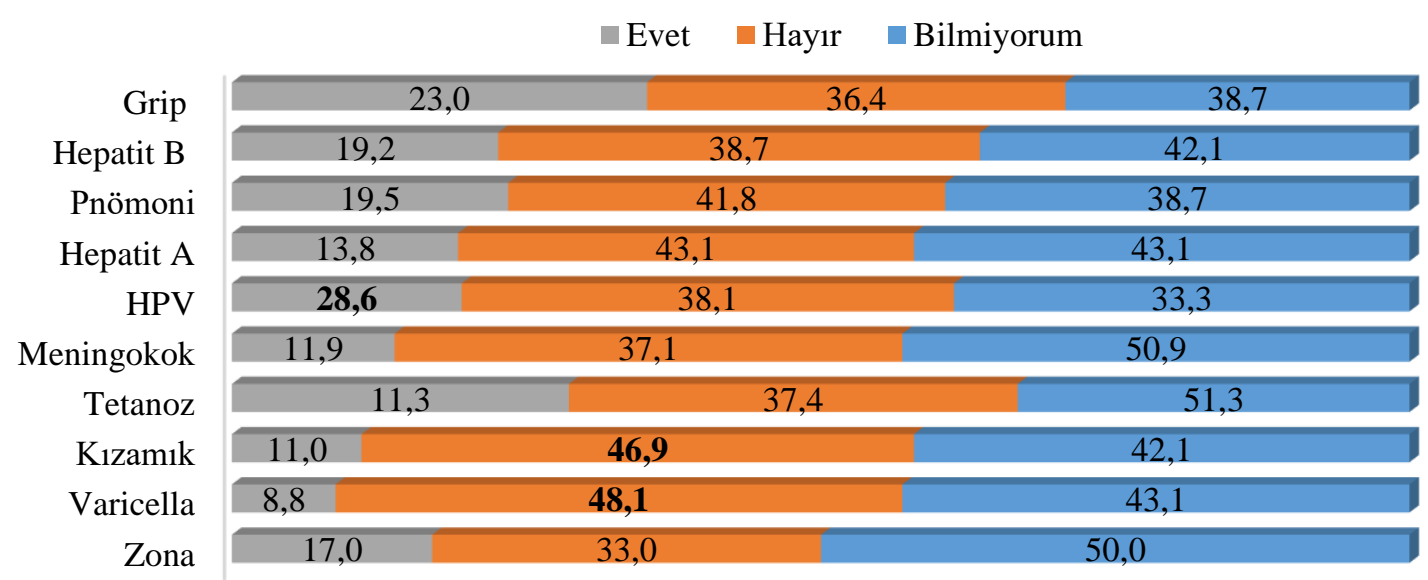

Grafik 2. Erişkinlerin aşıyla korunulan hastalıklar/etkenler açısından kendilerini risk altında görme durumları (\%)

Katılımcıların aşıyla korunulan hastalıklar açısından kendilerini risk altında görme durumlarıyla aşıları yaptırma oranları karşılaştırıldığında aşılar arasında farklılık gözlenmektedir. Grip, tetanoz, pnömoni ve hepatit B hastalıkları için kendilerini risk altında gören grubun görmeyen gruba göre bu hastalıklara karşı daha fazla aşılandığı anlaşılmaktadır (sırasıyla $\mathrm{p}=0,02 ; \mathrm{p}=0,006 ; \mathrm{p}=0,001 ; \mathrm{p}=0,002)$. KKK, hepatit A, varicella, zona, HPV ve meningokok aşıları için ise benzer bir anlamlı ilişki saptanmadı $(\mathrm{p}>0,05)$. 


\begin{tabular}{|c|c|c|c|c|c|c|c|c|c|c|c|c|}
\hline \multirow{3}{*}{ Özellikler } & \multicolumn{12}{|l|}{ Aşılar } \\
\hline & \multicolumn{2}{|l|}{ Grip } & \multicolumn{2}{|l|}{ Hepatit B } & \multicolumn{2}{|l|}{ HPV } & \multicolumn{2}{|l|}{ Pnömokok } & \multicolumn{2}{|l|}{ Zona } & \multicolumn{2}{|l|}{ Tetanoz } \\
\hline & $\mathrm{S}(\%)^{*}$ & $p$ & $\mathrm{~S}(\%)^{*}$ & $p$ & $\mathrm{~S}(\%)^{*}$ & $p$ & $\mathrm{~S}(\%)^{*}$ & $p$ & $\mathrm{~S}(\%)^{*}$ & $p$ & $\mathrm{~S}(\%)^{*}$ & $p$ \\
\hline \multicolumn{13}{|l|}{ Cinsiyet } \\
\hline Kadın & $202(91,0)$ & \multirow[t]{2}{*}{0,309} & $172(77,8)$ & \multirow[t]{2}{*}{0,839} & $125(39,3)$ & \multirow{2}{*}{0,001} & $129(58,1)$ & \multirow[t]{2}{*}{0,795} & $76(34,2)$ & \multirow[t]{2}{*}{0,348} & $195(87,8)$ & \multirow[t]{2}{*}{0,511} \\
\hline Erkek & $83(86,5)$ & & $73(76,0)$ & & $33(10,4)$ & & $58(60,4)$ & & $27(28,1)$ & & $81(84,4)$ & \\
\hline \multicolumn{13}{|l|}{ Yaş } \\
\hline $18-35$ & $94(87,9)$ & \multirow[t]{3}{*}{0,591} & $82(77,4)$ & \multirow{3}{*}{0,916} & $45(42,1)$ & \multirow[t]{3}{*}{0,002} & $59(55,1)$ & \multirow[t]{3}{*}{0,323} & $31(29,0)$ & \multirow[t]{3}{*}{0,610} & $94(87,9)$ & \multirow[t]{3}{*}{0,670} \\
\hline $36-64$ & $159(91,4)$ & & $137(78,7)$ & & $102(58,6)$ & & $104(59,8)$ & & $59(33,9)$ & & $151(86,8)$ & \\
\hline$\geq 65$ & $29(87,9)$ & & $25(75,8)$ & & $10(30,3)$ & & $23(59,2)$ & & $12(36,4)$ & & $27(81,8)$ & \\
\hline \multicolumn{13}{|c|}{ Eğitim durumu } \\
\hline$\leq$ Ortaokul & $119(83,2)$ & \multirow[t]{2}{*}{0,001} & $93(65,5)$ & \multirow[t]{2}{*}{0,001} & $59(41,3)$ & \multirow[t]{2}{*}{0,009} & $74(51,7)$ & \multirow[t]{2}{*}{0,028} & $35(24,5)$ & \multirow[t]{2}{*}{0,009} & $114(79,7)$ & \multirow[t]{2}{*}{0,001} \\
\hline$\geq$ Lise & $166(94,9)$ & & $152(86,9)$ & & $99(56,6)$ & & $113(64,7)$ & & $68(38,9)$ & & $162(92,6)$ & \\
\hline
\end{tabular}

*Ki Kare testi uygulanıp her grup kendi içinde karşılaşıtıılmıştır. 


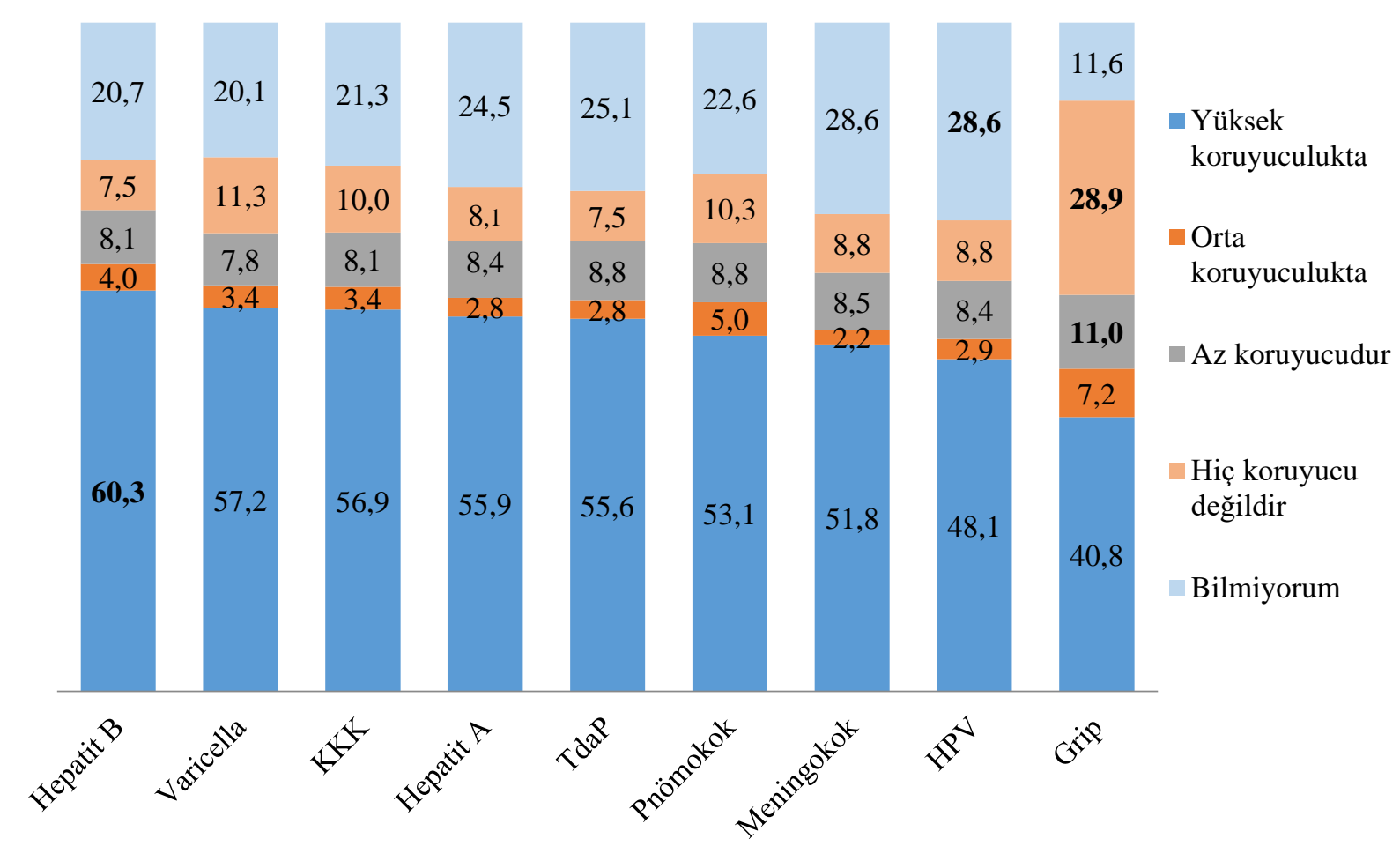

Grafik 3. Katılımcıların erişkin aşılarının koruyuculuğu hakkındaki fikirleri (\%)

Katılımcılara "Eğer yaptırmadığınız aşı varsa neden yaptırmadınız?" sorusu açık uçlu olarak yöneltildi. Yanıtlar gruplandi. Buna göre, katılımciların \%47,1'i "konu hakkında bilgilendirilmediğini”, \%43,2'si ise "aşıları yaptırmaya gerek duymadığını"; \%3,1'i “aşıların yan etkisi olduğunu düşündüğünü”; \%2,8'i “aşıdan korktuğu için yaptırmadığını”; \%2,2'si "bir sebebi olmadığını" belirtti.

Diğer sebepler "aşı zamanını tutturamama (grip için), bazı aşıların ücretlerinin sosyal güvence tarafından karşılanmamasıydı" $\quad(n=3, n=1)$. Katılımcılara "Eğer sosyal güvenceniz (sigortanız vs.) karşılasaydı aşılarınızı yaptırır mıydınız?" sorusu yönetildiğinde 178 'i “evet", 131'i "hayır", 9'u "emin değilim" yanıtını verdi. Erişkinlere aşılar hakkında en fazla bilgi edindiği kaynaklar sorulduğunda ise en fazla alınan yanıt medya $(n=118)$, daha sonra ASM'ler oldu. $(n=101)$. HPV aşısının erkeklere de uygulanabileceğini düşünenler katılımcıların \%16,7'sini $\quad(n=53)$ oluştururken. \%50'si buna gerek olmadığını, \%33,3'ü ise fikri olmadığını belirtti.

\section{TARTIŞMA}

Erişkin Aşıları Hakkındaki Bilgi ve Uygulama Durumu ve Sosyodemografik Özelliklerle İlişkisi

Araştırmamızda katılımcıların \%57,9'u hayatında en az bir kez erişkin aşıSı yaptırdığını belirtti. Antalya'da 2013'de Aşık ve ark. tarafından yapılan bir araştırmada bu değer \%59 iken ${ }^{17}$ Avrupa'da yapılan büyük ölçekli çok merkezli ADVICE ${ }^{18}$ araştırmasında ise medyan değer \%44,7 olarak bildirilmektedir. $\mathrm{Bu}$ araştırmada 24 Avrupa ülkesinin aşı yaptırma oranları ele alınmış ve minimum değer \%1 iken maksimum erişkin aş1 yaptırma oranı \%77,4 olarak bildirilmiştir. $\mathrm{Bu}$ ülkeler arasında maksimum erişkin aşısı yaptırma oranı olan ülkeler Hollanda ve Birleşik Krallık’tır.

Araştırmamızda erişkinler tarafından en çok duyulan, bilgi sahibi olunan ve yaptırılan aşılar grip, tetanoz ve hepatit $\mathrm{B}$ aşıları idi. Bu üç aşı, erişkin aşı takviminde erişkin yaş grubu için geniş risk gruplarına önerilen temel aşılardır. ${ }^{19}$ Aşık ve ark. ${ }^{17}$ ve bizim araştırmamızda erişkinlerin en fazla bilgi sahibi olduğu aşıların aynı sıralamayı takip ettiği görülmektedir (grip, tetanoz, hepatit B aşısı). Amerika'da 2015 'de yapılan geniş spektrumlu bir çalışmada erişkinlerin yaklaşık üçte birinin hepatit B, pnömokok ve HPV aşılarının erişkin dönem uygulamasından habersiz olduğu belirtilmektedir. ${ }^{20}$ Araştırmamız ile Aşık ve ark. nın araştırması karşılaştırıldığında sırasıyla tetanoz (Maltepe: $\% 42,1 /$ Antalya: 45,7); grip $(\% 23,9 / 29,6)$ ve hepatit B $(\% 18,2 / 17,0)$ en çok yaptırılan erişkin aşılarıdır. Türkiye'de 2006'da yayınlanan bir araştırmada erişkinlerde grip aşısının hedeflenenin yarısı, pnömokok aşısının dörtte bir oranında, hepatit B aşısının ise $\% 10$ oranında yapıldı ğı bildirilmektedir; tetanoz ve difteriye karş1 \%40 olması hedeflenen 
antikor pozitifliği ise \%20'lerdedir. ${ }^{21}$ Antalya'da aile sağlık merkezlerinde 2006'da yapılan başka bir araştırmada ise grip aşısı yaptırma oranı $\% 7,4$ olarak bildirilmiştir. ${ }^{22}$ Bütün bu verilere bakıldığında ülkemizde en çok bilinen ve yaptırılan aşılar açısından uygulamada bir yetersizlik durumu söz konusu olduğu söylenebilir.

Grip aşısı sağlıklı erişkinlerde \%70-90 koruma sağlarken, yaşlılarda grip ve komplikasyonlarını \%60 oranında azaltır ve gripten dolayı gerçekleşen ölümleri \%80 oranında düşürür. Grip aşısının tüm topluma, yılda bir kez yapılması önerildiğinden toplumda zaman içinde bir farkındalık oluşmuştur. Grip aşısı araştırmamızda en çok duyulan $(\mathrm{s}=285)$ aşı olmasına rağmen katılımcıların sadece \%24'ü aşıyı yaptırmıştı, \%66's1 ise aşıyı duymuş ancak yaptırmamıştı. Benzer şekilde 2014'te Türkiye'de 606 aile hekimiyle yapılan araştırmada aile hekimlerinin düzenli grip aşısı yaptırma oranı $\% 27,3$ olarak belirtilmektedir. ${ }^{23} \mathrm{Bu}$ iki araştırmanın sonuçları, solunum yolu hastalıklarının yüksek mortalite açısından \%11,1 ile, dolaşım sistemi hastalıkları $(\% 40,25)$ ve kanserlerden $(\% 20,04)$ sonra üçüncü sırada olduğu ülkemizde ${ }^{24}$, grip aşısının yaptırılma sıklığının yükseltilmesi gerektiğini göstermektedir.

Tetanoz aşısı araştırmamızda en çok bilgi sahibi olunan ikinci aşı olup, en yüksek yaptırılma oranına sahipti. Tdap ve Td aşılarının ise toplamda sadece 6 katılımcı tarafından yaptırıldığı saptandı. Burada katılımcıların kendilerine yapılan aşının sadece tetanoz toksoidi mi yoksa difteri tetanozu birlikte mi içerdiğini bilmediği varsayıldığından katılımcıların beyanı kabul edilmiştir. Tetanoz aşısı kadınların üreme çağında gebelikleri sırasında yaptırmaları önerilen bir aşı olduğundan, daha çok kadınlar tarafından bilinmekte ve yaptırılmakta olması beklenen bir sonuçtur. Tetanoz özellikle ileri yaşlarda koruyucu antikorların olmaması nedeni ile ölümcül seyretmektedir. Erişkin dönemde bu hastalıklardan korunmak için bağışık olmayan erişkinlerin 10 yıl arayla rapel yaptırmaları (tetanoz/ Td) önerilir. ${ }^{45}$

Erişkinlerde risk gruplarına yapılması önerilen hepatit B aşısı araştırmamızda en çok duyulan ikinci $(n=246)$ ve en çok yaptırılan üçüncü aşıydı ( $\mathrm{n}=58)$. Ancak bu aşının da katılımcıların $\% 23$ 'ü tarafından hala bilinmediği ve $\% 60$ 'a yakınının ise yaptırmadığı görüldü. Yaptırılmayan aşıların tümü için yaptırmama nedenleri sorulduğunda ilk sırada "bilgilendirilmeme, gerek görmeme, yan etkisi olduğunu düşünme" yanıtları alındı. Polonya'da yapılan ve Hepatit B aşısı ile ilgili bilgi düzeyi yüksek bulunan bir araştırmada erişkinlerin bilgiyi en çok medyadan ve sağlık personellerinden edindiklerini bildirilmektedir. ${ }^{25}$ Hepatit B aşısı çocukluk çağı aşı takvimine diğer aşılardan daha sonra girmiş olmasına rağmen, toplumda hepatit görülme sıklığının yüksek olması, virüsün kan ve kan ürünleriyle bulaşıyor olması nedeniyle toplumdaki farkındalığının yüksek olduğu söylenebilir. Aşının yaptırılmama nedeni ise muhtemelen bireyin kendini risk grubunda görmemesi ya da kendilerine sağlık çalışanları tarafından aşının önerilmemesi olabilir.

Araştırmamızda pnömokok aşısının katılımcıların \%59'u tarafından bilindiği, ancak katılımcıların \%50'sinin kronik hastalığı olmasına, $\% 11$ 'inin 65 yaş ve üzerinde olmasına rağmen aşının yaptırılma sıklığının toplamda $\% 4,7$ olarak bulunduğu saptandı. Kronik hastalığg olup 65 yaş ve üzerinde olan grup pnömokok aşısı yaptırma açısından diğer gruplarla karşılaştırıldığında aralarında anlamlı fark saptanmadı. Ülkemiz nüfusunun yaklaşık \%7'sini 65 yaş ve üzeri popülasyon oluşturmaktadır. Küresel olarak aşı ile önlenebilen hastalıklardan dolayı ölümlerde en yüksek paya sahip hastalığın streptokoksik pnömoni olduğu tahmin edilmektedir. T.C. Sağlık Bakanlığ ve Dünya Sağlık Örgütü (DSÖ) bu yaş grubuna, risk faktörü varlığına bakılmaksızın, grip ve pnömokok aşılarının yapılmasını kuvvetle önermektedir. ${ }^{26}$ Bağışıklama Uygulamaları Danışma Kurulu (Advisory Committee on Immunization PracticesACIP) erişkinlerde pnömokok aşısının; 65 yaş ve üzerinde olanlar, klinik alkolizm, kalp yetmezliği, kronik solunum sistemi hastalıkları, sigara kullanımı, karaciğer fonksiyon bozukluğu ve immün sistem yetersizliği olanlardan oluşan risk gruplarına yapılmasını önermektedir. Bu durumlarda invaziv pnömoni görülme riski yükseldiğinden, aşılama morbidite ve mortalitenin azaltılması açısından önemlidir. ${ }^{27}$ Pnömokok aşısı bu gruplarda öncelikli olarak önerildiğinden, toplumda farkındalık oluşturulması ve sağlık çalışanlarına yönelik, bu gruplara pnömokok aşısı danışmanlığı ve hizmet sunumu yapmaları açısından hizmet içi eğitimler verilmesi önerilir.

Human papilloma virusun (HPV)'nin; servikal kanser ile \%100, anal kanser ile \%90, diş genital organ kanserleri ile \%40, oral kanserlerle $\%$ ilo ilişkili olduğu düşünülmektedir. Servikal kanser, meme kanserinden sonra kadınlarda en sık görülen ikinci kanser türüdür ve dünyada her y1l 530.000 yeni vaka görülmektedir ve her y1l 270.000'den fazla kadın servikal kanserden dolayı hayatını kaybetmektedir. ${ }^{28}$ Tüm bu veriler servikal kanserin ve virüsün yol açtığı diğer komplikasyonların önemini göstermektedir. Bunlardan korunmanın en önemli yolu HPV aşılamasıdır. HPV aşısının her iki cinse de 12 ila 26 yaşları arasında yapılması önerilmektedir. ${ }^{29}$ Araştırmamızda $158 \quad(\% 49,6)$ katılımcının HPV aşısına dair bilgisi vardı; aşının önerildiği yaş grubuna en yakın olan 18-35 yaş grubunda yer alan 
katılımcılarda HPV aşısı hakkındaki bilgi düzeyi 3664 yaş grubuna göre daha düşük bulundu. Yani risk grubu aşının varlığından_daha az haberdardı. HPV aşısı bir kişi $(\% 0,3)$ ile yaptırılma oranı en düşük aşı olarak belirlendi ve katılımcıların \%50'si HPV aşısının erkeklerde uygulanmadığını belirtti. Karahasan ve ark. nın 546 üniversite öğrencisinde yaptığ araştırmada $^{30}$ ise HPV aşısı yaptırma oranı $\%$ 4,2 olarak bildirilmektedir $(\mathrm{n}=23)$. İki araştırma arasındaki bu farklılık katılımcıların eğitim ve yaş ortalaması farklılığından kaynaklanıyor olabilir. 2014'te Ankara'da yapılan Ulusal Aşı Çalıştayı'nda HPV aşısının önemi üzerinde durulmuş, ülkemizde yaptırılma oranının \%1'den az olduğu ve bunun nedeninin aşının yüksek maliyeti ve "rastgele cinsel ilişkiyi artırma endişesine yol açması" gibi nedenlerle açıklanmıştır. ${ }^{31}$ Çin'de yürütülen bir araştırmada HPV aşısı yaptırmadaki isteksizliğin nedenleri arasında; aşının güvenirliğinin az olduğunu savunma, HPV enfeksiyonu/genital siğil/servikal kanser açısından kendini riskli görmeme ve aşının yüksek ücreti gibi nedenler bildirilmektedir. ${ }^{32} \mathrm{Bu}$ bildirimler 1şığında aşının önündeki engellerin kaldırılması ve HPV aşısının rutin aşılama takvimine alınmasının aşının yaptırılma oranını artırabileceği söylenebilir.

Zona aşısı, 60 yaş ve üzerindeki her erişkine risk faktörü aranmaksızın önerilmektedir. Ancak hem araştırmamızda hem de Aşık ve ark. nın yaptı̆̆ 1 araştırmada $^{17}$ en az bilgi sahibi olunan aşı zona aşısıydı. Ayrıca araştırmamızda zona aşısı yaptırılma oranı \%0,9'du. Bu aşı satışa çok yeni çıktığından bilinmiyor olabileceği, ancak kısa sürede farkındalık oluşturulması gerektiği düşünüldü. Çünkü Zona özellikle yaşlı bireylerde lezyonlar ortadan kalktığı halde nöropatik ağrının bazen aylarca sürdüğü klinik durumlara yol açmakta ve bireylerin yaşam kalitesini ciddi şekilde olumsuz yönde etkilemektedir. Varicella aşısı, Varicella Zoster virüsünün tekrar aktifleşmesi sonucu oluşacak komplikasyonlardan ve post-herpetik nevraljiden korunmada en etkili yöntemdir. Varicella aşısı bağışık olmayan, hastalığa maruziyet riski yüksek olan ve aşının kontrendike olmadığı erişkinlere uygulanmalıdır. ${ }^{21}$

Araştırmamızda Varicella ve Kızamık Kabakulak Kıamıkçı (KKK) aşılarının erişkinlerde yaptırılma oranları düşük bulunmuştur (sirasıyla \%4, \%5). 1985-89 yilları arasındaki kızamık olgularının \%33'ü erişkinlerde bildirilmiştir. 1993'te bildirilen kabakulak olgularının \%20'si 20 yaş ve üzerindeki kişilerdedir. Genç erişkinlerin yaklaşık \%6-11'inin kızamıkçığa karşı bağışık olmadığı tahmin edilmektedir. ${ }^{33,34}$ Konjenital rubella sendromu, bağışıklığ olmayan kadınların bebeklerinde görülen ve malformasyonlarla seyreden konjenital bir enfeksiyondur. KKK aşısı canlı bir aşı olduğundan gebelikte yapılması kontrendikedir, o nedenle gebe kalmayı planlayanlar öncelikli olarak erişkin dönemde ve adolesan dönemde, aşının iki dozunun tamamlamalı, ayrica gebelikte de rutin olarak rubella antikoru bakılmalıdır.

Katılımcıların eğitim durumu göz önünde bulundurulduğunda lise ve üzeri eğitimi olanların grip ve hepatit B aşıları hakkında, ortaokul ve altı grubuna göre daha bilgili olduğu, bu aşıların koruyucu olduğu düşüncesinin de eğitimli grupta daha sık olduğu saptand. Pediyatrik aşıların uygulanmasında annelerin eğitim düzeyi aşıların yaptırılmasıyla ilişkili olan parametrelerden biri olarak bilinir. ${ }^{35}$ Erişkin aşıları ile ilgili eğitim düzeyinin etkisi hakkında İtalya'da yapılan bir araştırmada antiHBc pozitifliğinin düşük eğitim düzeyi ile doğru orantılı olduğu, ABD'de yapılan bir araştırmada da HPV aşısı ile ilgili bilgi düzeyinin eğitim düzeyi ile arttığı bildirilmektedir. ${ }^{36,} 37$ ABD'de yapılan başka bir araştırmada araştırmamızla örtüşür nitelikte, artan eğitim düzeyinin erişkinlerde influenza, Tdap, zona ve pnömokok aşılarının yaptırılması ile doğru orantılı olduğunu göstermektedir. ${ }^{38}$ Avrupa'da yapılan bir araştırmada ise erişkin aşılarının ücretsiz olduğu ülkelerde aşı yaptırma oranı eğitim düzeyi ile değişmezken, aşıların ücretli olduğu ülkelerdeki erişkinlerde eğitim düzeyi arttıkça erişkin aşılarının yaptırılma oranı da arttığı gösterilmektedir. ${ }^{39}$ Eğitim, sağlık okur-yazarlığını ve uygulamalarını etkileyen önemli bir unsur olmayı sürdürmektedir. ${ }^{40}$

Yaş grupları ve aşıların yaptırılma durumu karşılaştırıldığında; 65 ve üzeri yaş grubuna önerilen pnömokok, zona ve grip aşıları açısından bu grupla diğer yaş grupları arasında anlamlı bir fark saptanmad1. 2012'de Amerika'da Hastalık Kontrol ve Önleme Merkezi (Centers for Disease Control and Prevention-CDC) tarafindan yapilan araştırmalarda 65 yaş ve üzeri popülasyonun \%66'sının grip aşısını, \%60'ının pnömokok aşısını, $\% 20$ 'sinin de zona aşısını yaptırdığı ancak bu oranların Amerika'nın 2020 hedeflerini karş1lamadığg ve düşük olduğu bildirilmektedir. ${ }^{41}$

Erişkin aşıları hakkında bilgi edinilen kaynaklara bakıldığında araştırmamızda ve Aşık ve ark. nın yaptığı araştırmaya ${ }^{17}$ benzer sonuçlar elde edildiği saptandı. Bilgi edinilen kaynakların sırasıyla medya (Maltepe: \%33, Antalya:\%31) ve Aile Sağlı̆̆ Merkezleri (\%28, \%27) olduğu ortaya kondu. Amerika'da yapılan bir araştırmada da erişkin aşıları hakkında en çok bilgi edinilen kaynak medya olarak belirtilmektedir. ${ }^{41}$ Avusturya'da yapilan bir araştırmada erişkin aşılarını yaptırma konusunda erişkinlerin en çok aile hekimlerinden aldıkları bilgilere güvendikleri saptanmıştır. ${ }^{42}$ ASM'lerin en önemli bilgilendirme kaynaklarından biri olduğu düşünüldüğünde, aile hekimlerine erişkin aşılarıyla 
ilgili yapılacak eğitimlerin bu konudaki bilgi ve farkındalığı_artırmada, sağlık çalışanlarının varsa bu aşılar hakkındaki bariyerlerinin ortadan kaldırılması üzerinde etkili olabileceği düşünülmektedir.

Erişkin aşılarının koruyuculukları ile ilgili olarak, katılımcıların en çok koruyucu olduğunu düşündüğü aşıların sırası ile hepatit $\mathrm{B}$ ve tetanoz aşısı olduğu görüldü. Aşık ve ark. nın araştırmasında erişkinlikte en çok koruyucu olduğu düşünülen aşının tetanoz olduğu, grip aşısının koruyuculuğuna en az güvenilen aşı olduğu bildirilmektedir. ${ }^{17}$ İngiltere'de yapılan niteliksel bir araştırmada en çok bilgi sahibi olunan aşının grip aşısı olmasına rağmen koruyuculuğuna güvenilmemesinin nedeninin "Grip aşısının her yıl değişen içeriğinin yeterince test edilmeden piyasaya sürüldüğü" düşüncesi olduğu öne sürülmüştür. ${ }^{43}$ Halbuki grip epidemileri yılda 35 milyon kişide ciddi hastalık oluştururken, dünyada her yıl 250.000-500.000 kişi grip ve komplikasyonlarından dolayı hayatını kaybetmektedir. Erişkin dönemde bu hastalıktan korunmanın en etkili yöntemi aşılanmadır ve grip aşıs1 sağlıklı bireylerde \%70-90 koruma sağlamaktadır. ${ }^{26}$

Araştırmamızda erişkin aşılarını yaptırmama sebepleri ise en s1k "erişkin dönem aşıları hakkında bilgilendirilmeme” ve "bu aşıları yaptırmaya gerek görmeme" olarak saptand. Türkiye'de 2012'de Grip Platformu tarafindan yapılan bir diğer araştırmada ise erişkin aşılarının yaptırılmama sebebi "koruyuculuklarına güvenilmemesi" olarak belirtilmiştir. Avusturya'da yapılan araştırmada da benzer şekilde erişkin aşılarının yaptırılmama sebeplerinin başında 'yeterli bilgiye sahip olmama' gelmektedir. ${ }^{42}$ Araştırmamızda katılımcıların \%56'sı, sosyal güvenceleri bu aşıları karşılasa erişkin dönem aşılarını yaptıracağını belirtti, önceki soruda ise sadece bir katılımcı "karşılanmadı̆̆ından dolayı" aşıları yaptırmadığını belirtti. Araştırmamızda ve Aşık ve ark. nın yaptığı $\operatorname{araştırmada~}^{17}$, benzer şekilde katılımcılar "sadece belirli aşıların devlet tarafindan karşılandığııı" belirtmiş̧lerdir (sırasıyla \%46, \%40). Ülkemizde grip, tetanoz, pnömokok, hepatit A ve B aşıları erişkin dönemde ve risk gruplarında devlet tarafından karşılanmaktadır. ${ }^{45}$

\section{Erişkinlerin, Hastalıklar Hakkındaki Risk Algısı ve Aşı Yaptırma ile İlişkisi}

Araştırmamızda grip, tetanoz, pnömokok ve hepatit B hastalıkları için kendilerini risk grubunda görenlerin bu hastalıklara karşı daha fazla aşılandığı saptand1; KKK, varicella, hepatit A, zona, HPV ve meningokok aşılarında ise risk ve aşı yaptırma ilişkisi bulunmadı. Bu sonuçlar araştırmamızda en çok yaptırılan aşıların grip, tetanoz ve hepatit B aşıları olması ile örtüşmektedir. Kronik hastalık varlığı erişkinlerde risk faktörüdür ve risk grubu aşılamaları yapılmalıdır. Amerika'da 2012'de CDC tarafından yapılan bir araștırmada 19-64 yaş grubunda olup pnömokok aşısı için risk grubunda bulunan erişkinlerin \%20'sinin, 65 yaş ve üzeri erişkinlerin ise \%60'1nın pnömokok aşısını yaptırdığı belirtilmektedir. ${ }^{41}$ Avrupa'da yapılan bir araştırmada $^{18}$ kronik hastalık varlığı ile grip aşısı yaptırma oranı ilişkili olup risk grubunun \%45,6'sının grip aşısını yaptırdığı bildirilmektedir. Danimarka'da yapılan bir araştırma 65-80 yaş arası erişkinlerde; sırasıyla kalp-damar hastalıkları, kronik akciğer hastalıkları ve diyabetin mevsimsel influenza aşısını yaptırmada en etkili faktörlerden biri olduğunu göstermiştir. Araştırmada mevsimsel grip aşısını yaptıran $65-80$ yaş arası erişkinlerin bu aşıyı yaptırmasında en önemli kurumun birinci basamak sağlık merkezleri olduğu ortaya konulmuştur. ${ }^{44}$ Araştırmamızda kronik hastalığ olanlarla olmayanlar arasında, erişkin aşılarını yaptırma açısından anlamlı bir fark saptanmadı. Bu veriler bize kronik hastalığı olan bireylerin aşı yaptırmaları gerektiğinin farkında olmadıkları yönünde ipucu vermekte, bu görüş yukarıda belirtilen araştırmaların bildirdiği sonuçlarla da uyuşmaktadır. Kronik hastalık yönetiminde aşı ile bağışıklanma konusunda bireylerde daha fazla farkındalık yaratılması ve sağlık hizmeti verenlerin bu konuda desteklenmesi gerekmektedir.

\section{Araștırmanın Kısıtlılıkları}

Çalışmanın tanımlayıcı yönde yapılmış olması ve sadece ASM'ye başvuran kişileri kapsaması çalışmamızın kısıtlılıklarındandır. Buna ek olarak araştırmamız bölgesel olup, sadece Maltepe ilçesini içermektedir, tüm erişkinleri temsil etmemektedir.

\section{SONUC}

Araştırmamızın bulguları erişkin dönem aşılarının hem farkındalık hem de yaptırılma oranlarının düşük olduğunu göstermektedir. Erişkin aşıları hakkında bilgi sahibi olma durumunda lise ve üzeri eğitimli olmak fark yaratmaktadır. Zona ve HPV aşılarının bilinirliği az olduğundan topluma tanıtılması gereklidir. Medya bireylerin aşılar hakkında en fazla yararlandıkları kaynaktır, diğer en önemli kaynak birinci basamak sağlık kurumlarıdır. Erişkin aşılama oranlarının yükseltilmesi için sağlık çalışanlarının güncel bilgilerle desteklenmesi, hizmet içi eğitimler ve varsa engellerin kaldırılmasına yönelik çalışmalar yapılması; halkın konuyla ilgili farkındalığının artırılmasına katkıda bulunacaktır. Medyada doğru bilgilendirme yapılması da farkındalığın ve uygulamaların artırılması açısından önemlidir. 


\section{KAYNAKLAR}

1. CDC (2014) Benefits from Immunization During the Vaccines for Children Program EraUnited States, 1994-2013. MMWR 63: 352355.

2. Sutter RW, Tangermann RH, Aylward RB, Cochi SL. Poliomyelitis eradication:progress, challenges for the end game, and preparation for the post-eradicationera. Infect Dis Clin North Am. 2001 Mar;15(1):41-64. Review. PubMed PMID:11301822.

3. Swanson K. A., Schmitt H. J., Jansen K. U., Anderson A. S.: Adult Vaccination. Human Vaccines\&Immunotherapy, 2015 Jan; 11(1): 150-155.

4. Meites E., Kempe A., Markowitz L.E. Use of a 2-Dose Schedule for Human Papillomavirus Vaccination-Updated Recommendations of the Advisory Committee on Immunization Practices. Am J Transplant. 2017 Mar;17(3):834-837.

5. Advisory Committee on Immunization Practices (ACIP). General Best Practice Guidelines for Immunization. https://www.cdc.gov/vaccines/hcp/aciprecs/index.html. Erişim tarihi: 20.01.2018

6. The 2009 Ageing Report: economic and budgetary projections for the EU-27 Member States

(2008-2060). http://ec.europa.eu/economy_finance/publicati ons/pages/publication14992_en.pdf Erişim tarihi: 26.06.2018

7. Bureau UC. Population by Age and Sex for the United States: 1900 to 2000. PartA Census 2000 Special Reports, Series CENSR-4: US Administration on Aging., 2002, (p. 58-59)

8. US Census Bureau PD. Projections of the Population by Age and Sex for the United States: 2010 to 2050. US Census Bureau, Population Division, 2008, (p. 4)

9. Mangili A, Gendreau M. A. Transmission of infectious diseases during commercial air travel. Lancet. 2005 Mar 12-18;365(9463):989-96. Review.

10. Annunziata K, Rak A, Buono H. D., DiBonaventura M, Krishnarajah G. Vaccination Rates among the General Adult Population and High-Risk Groups in the United States., Journal of Public Library of Science Medicine 2012; (p. 4).

11. Bechini A, et al. Acellular pertussis vaccine use in risk groups (adolescents, pregnant women, newborns and health care workers): a review of evidences and recommen-dations. Vaccine 2012;30(35):5179-90.

12. Lavine $\mathbf{J}$, et al. Imperfect vaccine-induced immunity and whooping cough transmis-sion to infants. Vaccine 2010;29(1):11-6.
13. Rozenbaum MH, et al. Modelling the impact of extended vaccination strategies on the epidemiology of pertussis. Epidemiol Infect 2012;140(8):1503-14.

14. Erişkin Bağışıklama Rehberi 2006. http://meramtip.com.tr/kalite/dosyalar/rehberle r/eriskin-

bagisiklama/EriskinBagisiklamaRehberi.pdf 21.02.2018 tarihinde erişilmiştir.

15. Fact sheet: Hepatitis A[Internet]:World Health Organization; 2013 July. Available from: http://www.

who.int/mediacentre/factsheets/fs328/en/

[accessed on 27 September 2013].

16. Türkiye İstatistik Kurumu (TÜİK), Hastanelerde Yatan Hastaların Seçilmiş 150 Hastalık Nedenine Göre Dağılımı. Erişim: http://www. tuik.gov.tr/ VeriBilgi.do?alt_id=6 Erişim Tarihi: 13.06.2012

17. Aşık Z., Çakmak T., Bilgili P.: Erişkinlerin Erişkinlik Dönemi Aşıları Hakkındaki Bilgi, Tutum Ve Davranışları. Türk Aile Hekimliği Dergisi 2013;17(3):113-118.

18. Ozisik L, Tanriover M.D, Rigby S, Unal S: ADVICE for a healthier life: Adult Vaccination Campaign in Europe. European Journal of Internal Medicine 33 (2016) 14-20.

19. Türkiye Enfeksiyon Hastalıkları ve Klinik Mikrobiyoloji Uzmanlık Derneği Erişkin Bağışıklama Rehberi Çalışma Grubu, Erişkin Bağışıklama Rehberi 2. Güncelleme- 2016, s. 85-87

20. Peng-jun L, O’Halloran A, Kennedy ED. Awareness among adults of vaccinepreventable diseases and recommended vaccinations, United States, 2015. Vaccine 2017;35:3104-15.

21. Köksal I, Usluer G. Erişkinlerde aşılama. ANKEM Dergisi 2006;20:239-45.

22. Oncel S, Turhan O, Huseyin PH, Yalcin AN. Status of influenza vaccination in patients presenting to two neighborhood primary health care clinics inAntalya. Infez Med 2008;16:749.

23. Akan H, Yavuz E, Yayla M.E, Külbay H, Kaspar E.Ç, Zahmacıoğlu O, Badur S. Factors affecting uptake of influenza vaccination among family physicians, Vaccine 34 (2016) 17121718.

24. T.C Sağlık Bakanlığ 1 Sağlık İstatistikleri Yıllı̆̆ 2015, SB-SAGEM-2016/1, s.27

25. Ganczak M., Dmytrzyk-Daniło'w G., Korzen' M., Drozd-Da,browska M., Szych Z. Prevalence of HBV Infection and Knowledge of Hepatitis B Among Patients Attending Primary Care Clinics in Poland. J Community Health (2016) 41:635-644.

26. Mehta B., Chawla S., Kumar V., Jindal H., Bhatt B.: Adult Immunization, The need to adress. Human \&accines \& 
Immunotherapeutics c 2014 Landes Bioscience February 2014; 10:2, 306-309

27. Centers for Disease Control and Prevention, Use of 13-Valent Pneumococcal Conjugate Vaccine and 23-Valent Pneumococcal Polysaccharide Vaccine Among Adults Aged $\geq 65$ Years: Recommendations of the Advisory Committee on Immunization Practices (ACIP). MMWR Morb Mort Wkly Rep, 63 (2014), pp. 822-825

28. Fact Sheet. Human Papillomavirus (HPV) and Cervical Cancer[Internet]:World Health Organization;2016 June. Available from: http://www.who.int/mediacentre/factsheets/fs3 80/en/ Erişim tarihi: 07.08.2017

29. Yaseman JG, Koutsky LA. The epidemiology of human papillomavirus infections. J Clin Virol 2005;32(Suppl 1):s. 16-24

30. Karahasan A, Dündar O.H, Öztürk E.N, Soyiç K, Hediye A, Gül U. Marmara Üniversitesi öğrencilerinin cinsel sağlık yönünden bilgi ve tutumlarının değerlendirilmesi. 16. Marmara Üniversitesi Tıp Fakültesi Öğrenci Kongresi Bildiri Kitapçı̆̆ı 2016, (s. 23).

31. Ulusal Aşı Çalıştayı Raporu, Ankara, Mart 2014, s. 45-48 http://www.geriatri.org.tr/pdf/Ulusal_Asi_Calis tayi_Rapor_2014.pdf Erişim tarihi: 20.11.2017

32. Yanru Z., Ying W., Li L.: Awareness and knowledge about human papillomavirus vaccination and its acceptance in China: a metaanalysis of 58 observational studies: Zhang et al. BMC Public Health (2016) 16:216 DOI 10.1186/s12889-016-2873-8.

33. Centers for Disease Control and Prevention: Update on adult immunization: recommendations of the Immunization Practices Advisory Committee (ACIP), MMWR 1991;40(RR-12):1-94

34. Fedson D: Adult immunization: summary of the National Vaccine Advisory Committee report, JAMA 1994;272(14):1133-7.

35. İşler A, Esenay F.I, Kurugöl Z, Koturoğlu G. Annelerin aşılar konusundaki bilgi ve davranışları, Ege Pediatri Bülteni 2007,14(1):16.

36. Morisco F., Stroffolini T., Lombardo F.L., Guarino M., Camera S., Cossiga V., Donnarumma L., Loperto I., Caporaso N. Prevalence of and risk factors for $\mathrm{HBV}$ infection in a metropolitan Southern Italian area: Evidence for the effectiveness of universal Hepatitis B vaccination. Digestive and Liver Disease, Volume 49, Issue 11, November 2017, Pages 1257-1261.

37. McBride KR, Singh S. Predictors of Adults' Knowledge and Awareness of HPV, HPV-
Associated Cancers, and the HPV Vaccine: Implications for Health Education. Health Educ Behav. 2018 Feb;45(1):68-76.

38. La E.M., Trantham L., Kurosky S.K., Odom D., Aris E., Hogea C. An analysis of factors associated with influenza, pneumoccocal, Tdap, and herpes zoster vaccine uptake in the US adult population and corresponding inter-state variability. HUMAN VACCINES \& IMMUNOTHERAPEUTICS 2018, VOL. 14, NO. 2, 430-441.

39. Jain A., van Hoek A.J., Boccia D., Thomas S.L. Lower vaccine uptake amongst older individuals living alone: A systematic review and meta-analysis of social determinants of vaccine uptake. Vaccine 35 (2017) 2315-2328.

40. Öztürk Z, Atilla E.A, Koç E. Aile sağlı̆̆ merkezlerine başvuran hastaların demografik özellikleri ve sağlık okur yazarlıkları arasındaki ilişkinin belirlenmesi, Turkiye Sosyal Arastirmalar Dergisi; 8/1/2015, Vol. 19 Issue 2, p. 263-284.

41. Williams WW, Lu PJ, O'Halloran A, Bridges CB, Pilishvili T, Hales CM, Markowitz LE; Centers for Disease Control and Prevention (CDC). Noninfluenza vaccination coverage among adults - United States, 2012. MMWR Morb Mortal Wkly Rep 2014; 63:95-102; PMID:24500288

42. Sandhofer M.J., Robak O., Frank H., Kulnig J. Vaccine hesitancy in Austria, A cross-sectional survey. Wien Klin Wochenschr (2017) 129:5964.

43. Wheelock A., Parand A., Rigole B., Thomson A., Miraldo M., Vincent C., Sevdalis N.: SocioPsychological Factors Driving Adult Vaccination: A Qualitative Study. PLoS One. 2014; 9(12): e113503.

44. Hellfritzsch M., Thomsen R.W., Baggesen L.M., Larsen F.B., Sørensen H.T., Christiansen C.F. Lifestyle, socioeconomic characteristics, and medical history of elderly persons who receive seasonal influenza vaccination in a taxsupported healthcare system. Vaccine 35 (2017) 2396-2403.

45. Erişkin Bağışıklama Rehberi: EKMUD, Mayıs 2016, $\quad$ s. 25 http://meramtip.com.tr/kalite/dosyalar/rehberle r/eriskinbagisiklama/EriskinBagisiklamaRehberi.pdf Erişim tarihi: 25.11.2017 